\title{
Using a terrestrial laser scanner to detect wood characteristics in gravel-bed rivers
}

\author{
Alessia Tonon, Lorenzo Picco, Diego Ravazzolo, Mario Aristide Lenzi \\ Department of Land, Environment, Agriculture and Forestry, University of Padova, \\ Legnaro (PD), Italy
}

\begin{abstract}
The possibility of analysing the characteristics and volume of inchannel large wood (LW) is of importance for river management but the traditional manual field activities are usually time-consuming and not easy to apply at a larger spatial scale. This paper presents an alternative and faster method to detect the characteristics and measurements of large wood in rivers by using the terrestrial laser scanner (TLS) technology. Field-measurements data and TLS scans were collected in August 2013 along 14 ha of the Piave River (Italy) analysing 230 and 208 woody elements for the manual method and the TLS one, respectively. TLS data were processed using the Cyclone 7 software and the LW measurements were extracted adopting two specific tools. The resulting low margin of error in the comparison between field data and those derived from TLS surveys confirmed the ability of TLS in the detection of large wood and wood jams characteristics. The greatest deviations were found for wood jams height which the TLS showed a tendency to overestimate $(+24.37 \%)$ and $\mathrm{LW}$ length with a slight underestimation $(-19.76 \%)$. Considering the wood volume, the relative difference between the TLS and manual method was within a negligible margin of error of $\pm 7 \%$. Characteristics and measurements of LW in rivers can be obtained from TLS surveys, but some progress in
\end{abstract}

Correspondence: Lorenzo Picco, Department of Land, Environment, Agriculture and Forestry, University of Padova, 35020 Legnaro (PD), Italy. E-mail: lorenzo.picco@unipd.it

Key words: gravel-bed river, large wood, Piave River, terrestrial laser scanner.

Acknowledgements and funding: this research was funded by the project SedAlp: sediment management in Alpine basins, integrating sediment continuum, risk mitigation and hydropower, 83-4-3-AT, in the framework of the European Territorial Cooperation Program Alpine Space 2007-2013, and by the Italian National Research Project PRIN 2014 ALME4 - IT SedErosion: National network for monitoring, modelling and sustainable management of erosion processes in agricultural land and hilly-mountainous area. The authors thank Alison Garside for revising the English text.

Received for publication: 30 July 2014.

Accepted for publication: 12 November 2014.

CC Copyright A. Tonon et al., 2014

Licensee PAGEPress, Italy

Journal of Agricultural Engineering 2014; XLV:431

doi:10.4081/jae.2014.431

This article is distributed under the terms of the Creative Commons Attribution Noncommercial License (by-nc 3.0) which permits any noncommercial use, distribution, and reproduction in any medium, provided the original author(s) and source are credited. this technique is still needed to allow a better management of the 3D point cloud and a faster extraction of the wood measurements. The proposed method represents an alternative tool for faster and repeated surveys of wood characteristics in a complex river environment, ensuring a reliable quantification of spatial and temporal variation of wood volume.

\section{Introduction}

Braided rivers are complex environments with at least two channels separated by bars and islands (Leopold and Wolman, 1957) that undergo frequent morphological adjustments, such as erosional and depositional processes, even after ordinary flood events. Gravel-bed braided rivers often have riparian woodlands along their banks that are frequently eroded, transported and deposited by floods (Gurnell et al., 2005). The assessment of the spatial distribution and amount of large wood (LW) in a riverine environment is a key factor under many aspects, including fluvial dynamics (Piegay, 2003), biodiversity (Gurnell et al., 2005), carbon sequestration (Guyette et al., 2002), and natural hazards (Mazzorana et al., 2009). In fact, wood is important for its influence on the structural complexity of a riverine environment (Keller and Swanson, 1979; Bilby and Ward, 1989) as well as on floodplain dynamics (Wohl, 2013). In-channel wood plays an important role on the morphological changes accelerating the process of fluvial islands formation (Gurnell et al., 2005), and causing local or channelwide aggradation due by sediment retention processes (Mao et al., 2008; Wohl, 2013). Moreover, from an ecological point of view, the wood is a source of organic matter for macro and micro invertebrates and promotes pool formation (Rosenfeld and Huato, 2003), offering refuge for a variety of aquatic organisms. However wood does not just have positive feedbacks on the riverine environments, as it can increase flood hazards, particularly in correspondence to critical crosssections or close to man-made structures (Diehl, 1997; Comiti et al., 2008; Mazzorana et al., 2009).

As a result, wood has gained greater attention in riverine environment management, at both basin and fluvial scale (Montgomery and Piégay, 2003; Mao et al., 2008). Knowledge on the dynamics of wood in rivers and its interactions with other fluvial components (e.g. morphological units, vegetation, sediments) can be useful to ensure a proper management of in-channel wood. Notably, information on the amount of wood in a water course as well as the transport capacity are required for defining correct management approaches, for design suitable retention structures and to better prevent wood influence on critical sections (Comiti et al., 2012).

In this context, the increasing attention on the role of $\mathrm{LW}$ in rivers and torrents has led to the development of new methods for an efficient recognition of in-channel wood. The traditional measuring techniques are based on manual surveys in the field, which are very timeconsuming. Moreover, the conventional approach is often difficult to 
apply at a large spatial scale. To overcome this limit, considerable attention has been given to the possibility of using remote-sensing techniques that could provide data at a lower cost than the traditional field inventories (Næsset 2004; Holopainen and Talvitie, 2007). These techniques, including airborne laser scanner and terrestrial laser scanner (TLS), enable the acquisition of three-dimensional data of scanned objects, with specific $x, y$ and $z$ coordinates.

Since 2003, numerous studies have explored the ability of TLS technology in a forest environment both for individual trees and accumulations. For instance, it has been used to estimate fire behavior by mapping volumes of fuel wood (Seielstad and Queen, 2003), to automatically reconstruct single stand trees in a stand (Pfeifer et al., 2004) and to estimate the percentage of dead trees in unmanaged forests (Bater $e t$ al., 2007).

Despite the extensive application of TLS for the recognition of wood parameters in a forest, there are few studies in the literature focusing on the capacity of this device to provide reliable information on wood in a complex fluvial environment, such as a gravel-bed river. This kind of technology could represent a useful tool for river applications, allowing rapid and accurate acquisition of data at a medium spatial scale. These data would permit us to assess the amount, variability and spatial distribution of wood in rivers.

The aims of the present study are: i) to evaluate the ability of TLS to provide the main wood characteristics needed for wood volume assessment along two sub-reaches of a gravel-bed river; ii) to conduct a qualitative analysis to define parameters like shape, wood type and orientation.

\section{Study area}

The study was conducted along the Piave River, a gravel-bed river located in Veneto region (north-eastern Italy). The Piave River flows for about $220 \mathrm{~km}$ from the Alpine region (at $2037 \mathrm{~m}$ a.s.l.) to the Adriatic Sea. The drainage basin covers an area of $3899 \mathrm{~km}^{2}$ characterised by sedimentary rocks (mainly limestone and dolomite). The entire river catchment lies in a humid and temperate continental climate zone with an average annual precipitation of $1350 \mathrm{~mm}$. Floods occur mainly in summer and autumn connected with snowmelt, rainstorms and the rainiest periods. The river course can be divided into three main zones with different features. In the upper part, the river is incised in bedrock and has a quite narrow channel, whereas in the middle part it forms a multithreaded channel pattern with a wide valley. In the lower part of its course, the river has a meandering morphology alternating with reaches confined by artificial embankments (Surian, 1999).

The research was conducted in two study areas (Figure 1) located along the middle course of the river. The first area is upstream of Belluno and shows a braided morphology whereas the second, downstream of Belluno, features a wandering channel pattern. In this reach the riverbanks are bordered by riparian vegetation dominated by Salix spp. and Populus spp. that ensure a constant supply of large wood. Further details on the flow regime, morphology, islands dynamics and riparian woody communities, of the Piave River and basin, are available in the literature (Comiti et al., 2011; Picco et al., 2012a, 2012b; Rigon et al., 2012; Delai et al., 2014; Kaless et al., 2014; Picco et al., 2014a, 2014b).

\section{Materials and methods}

Field data and TLS surveys were collected along the study area dur- ing a field survey campaign in August 2013. Wood elements were identified with diameter greater than $10 \mathrm{~cm}$ and/or length more than $1 \mathrm{~m}$ (Jackson and Sturm, 2002). Both single pieces of LW and wood jams (WJ) were included, in order to explore the considerable variability of wood and the ability of TLS to recognise it. We considered the WJ as heterogeneous accumulations of woody of various sizes (Thevenet $e t$ $a l ., 1998)$, whereas the large wood pieces were further divided in logs, trees and shrubs. During the traditional field activities a total of 230 wood elements were analysed: 100 wood jams and 130 large woods.

Traditional tape and tree calibre were used for the detection of the main wood characteristics. For the wood jams, the length (JL), width (JW) and height (JH) were considered. For each large wood, notably logs and trees, the log length (LL) and diameter at a breast height (LD) were taken into account, whereas for shrubby elements measuring the diameter of each branch was time-consuming so the tree canopy width (TCW) was considered. Adopting the traditional volume estimation method developed by Piegay (1993), Citterio (1996) and Thevenet et al. (1998), the volume of each element was then calculated assuming a solid cylindrical shape and a solid parallelepiped shape for single wood and wood jam, respectively. The results obtained from these geometrical forms provided the information related to air-wood volume.

Simultaneously to the traditional measurements, TLS surveys were conducted. The device used in this study (Leica Scan Station 2; Leica Geosystems AG, Heerbrugg, Switzerland) is a pulsed TLS that collects up to 50,000 points per second at a spatial resolution higher than one point per $\mathrm{mm}^{2}$ at $100 \mathrm{~m}$. Unlike the methodology presented by Boivin and Buffin-Bélanger (2010), in this study TLS data were collected following a geomorphic approach, with the spatial distribution and settings proposed by Picco et al. (2013). The position of the TLS within the study area was defined according to the presence of large wood and the complexity of the topographic surface, in order to obtain a uniform density in the whole study area. This approach was adopted because of the highly time-consuming process for the specific detection presented by Boivin and Buffin-Bélanger (2010); in fact no targeted scans were performed around single woody elements. Considering this, 15 and 13 scans were carried out in an area of 8 ha (upper reach) and 6 ha (lower reach) respectively, obtaining a point density of about 2000 points $/ \mathrm{m}^{2}$. The individual point clouds produced by the TLS were registered and georeferenced using the Cyclone 7 software, developed by Cyra Technologies Inc. (San Ramon, CA, USA).The wood measurements were virtually extracted from the point clouds using Point to point or Limit box methods (Figure 2). The former was used for the large wood

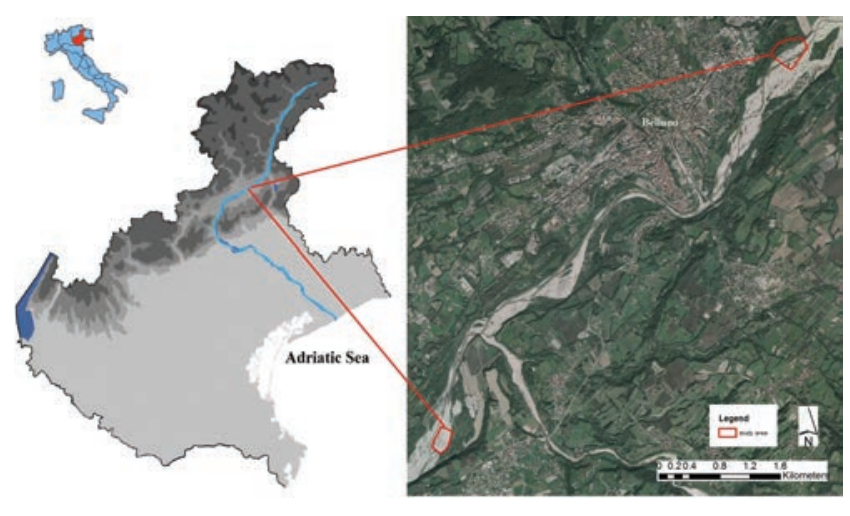

Figure 1. The Piave River in the Veneto region (on the left) and the two study areas in Belluno province. Flow direction is down the page. 
detection and the latter only for the wood jams, by a parallelepiped box enclosing the woody accumulation. Wood volume was computed as described above. Statistica software, developed by Statsoft (Tulsa, OK, USA), was used to compare the results obtained by the traditional and TLS methods. In terms of fieldwork costs, field surveys were conducted in a three-day timespan both for the traditional and TLS surveys. A team of four operators was required for the traditional measurements, whereas only one person was sufficient for the TLS surveys. Three days were needed to process the data collected by manual methods. Instead, two days were enough to extract wood dimensions from the point cloud.

\section{Results}

Overall, 230 (100 wood jams and 130 large wood) and 208 (89 wood jams and 119 large wood) woody elements were analysed for the manual and the TLS-method, respectively. The large wood have a diameter between $0.10 \mathrm{~m}$ and $0.50 \mathrm{~m}$, whereas the length ranges from $1 \mathrm{~m}$ to 10 $\mathrm{m}$. Focusing on the capacity of TLS to detect the main wood characteristics, the 3D point clouds were analysed in detail. Considering the wood jams, no significant differences were found between the results obtained by the traditional and experimental methods (Figure 3). TLS demonstrated its ability to extract the details accurately; indeed the median values of TLS data are very close to the manual ones. The JL shows a median value of $6.30 \mathrm{~m}$ whereas from the TLS data it is $6.64 \mathrm{~m}$, with an overestimation of about $+5.12 \%$. The JW presents a median value of $3.90 \mathrm{~m}$ and $3.91 \mathrm{~m}$ for manual and TLS data, respectively. In this case, the overestimation is very low and equal to $+0.25 \%$. The third measure, JH, shows a slight overestimation by the TLS of about $+17.80 \%$, providing a median value of $0.73 \mathrm{~m}$ with respect to the $0.60 \mathrm{~m}$ of the manual data. Looking at the median values reported in the graph (Figure 4), we could appreciate the capacity of TLS to provide a reasonable estimation of wood jams characteristics. The results obtained from the point clouds are very similar to those derived from the fieldwork $(+3.95 \%$ and $-3.49 \%$ relative difference ranges for JL and JW, respectively) except for the jam height when the TLS strongly overestimated the median value $(+24.37 \%$ relative difference range). Figure 5 shows the trend of the estimated errors for the wood jams measurements derived from TLS data. The only significant relationship is displayed by the TLS-derived JL $(\mathrm{P}=0.0382)$ which shows a decrease in errors estimation with longer jams. Notably, the variability of errors tends to reduce in correspondence to length values greater than $7 \mathrm{~m}$. JW and JH show a not significant relationship with the errors estimation without a clear distribution of values, in this case errors seem to be independent of wood jams size.

The ability of TLS to provide clear data is also confirmed by the results regarding the large wood (Figure 6). The best agreements between the two datasets were found for the diameter and tree canopy width, with values extremely similar to one another. The median value of LD is $0.12 \mathrm{~m}$ for both methods, whereas TCW shows a median value of $1.60 \mathrm{~m}$ for surveyed data and $1.62 \mathrm{~m}$ for TLS. The slight overestimation is equal to $+1.23 \%$. The capacity of TLS seems to be weakest regarding the LL estimation as it provides an underestimation of about $-29.41 \%$, with a median value shifting from $3.30 \mathrm{~m}$ of surveyed data to $2.55 \mathrm{~m}$ of TLS data. This is illustrated in Figure 7, which reports the relative difference ranges. Focusing on the median values, it can be observed that there is a good correspondence between the manual and TLS methods. The measurements with TLS tend to slightly overestimate the $\mathrm{LD}$ and TCW by negligible values: $+5.16 \%$ and $+0.37 \%$, respectively. There is a greater difference between the surveyed data and those obtained from scans for the LL, with the TLS data providing a quite considerable underestimation of about $19.76 \%$. Looking at the

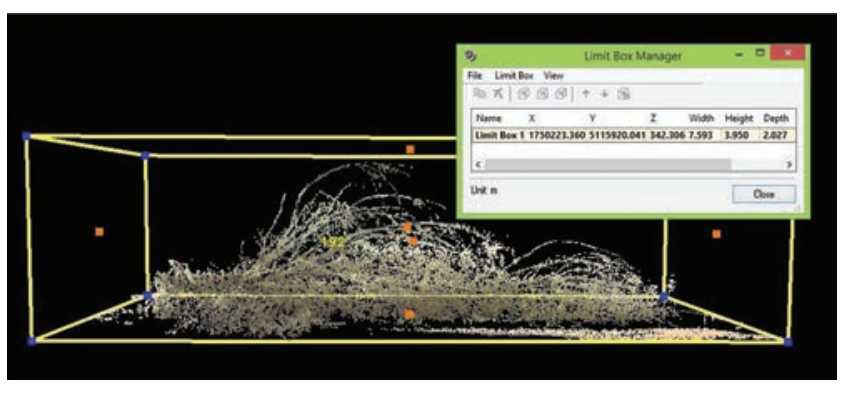

Figure 2. Wood jams measurement using Limit box method.

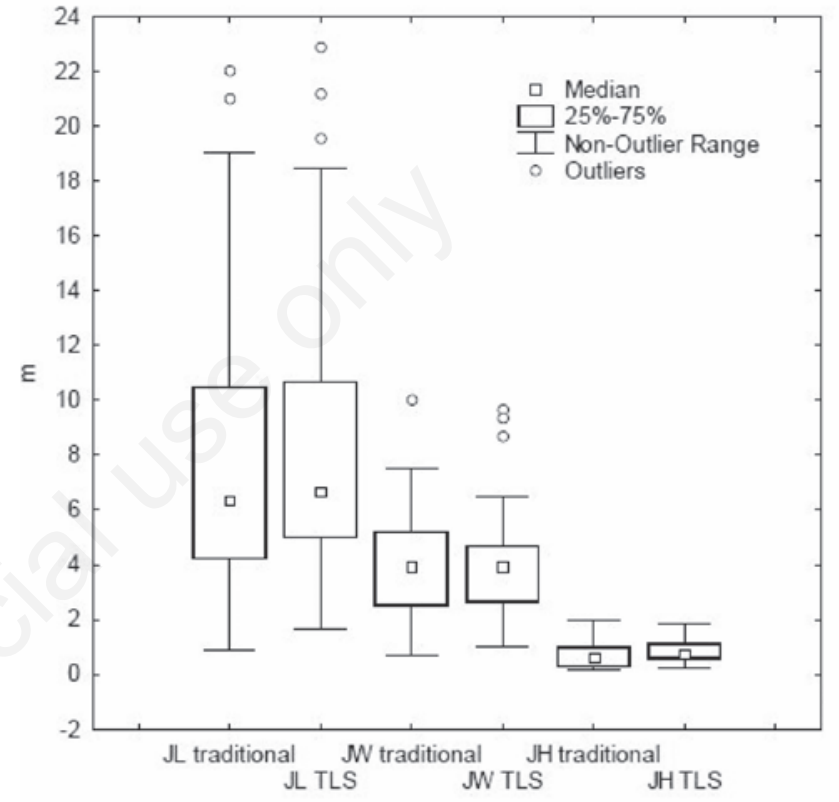

Figure 3. Comparison between traditional results and terrestrial laser scanner (TLS) results for the three main woods jams measurements. JL, length; JW, width; JH, height.

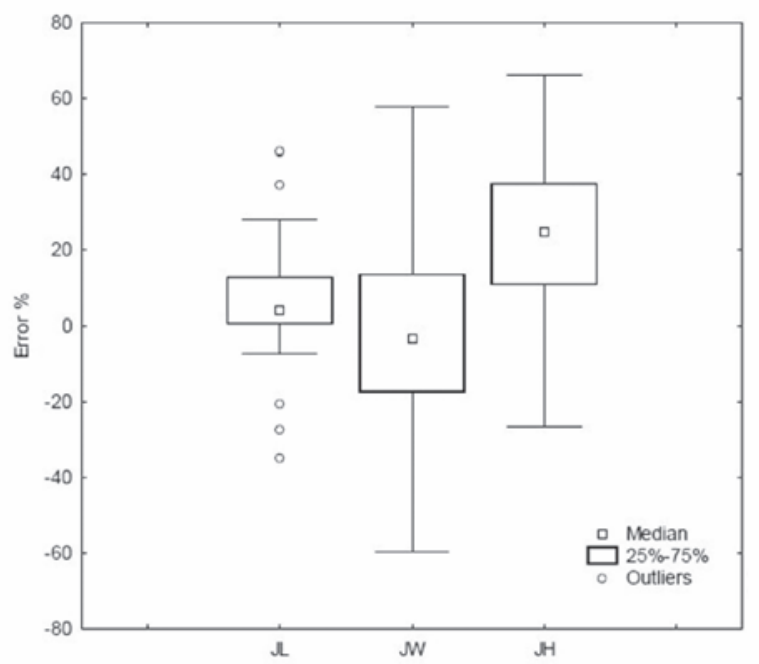

Figure 4. Relative differences of the terrestrial laser scanner method when compared to the manual ones for the three main wood jams measurements estimation. JL, length; JW, width; JH, height. 
distribution of the errors estimation according to the large wood measurements (Figure 8), the TLS-derived LL is the only one showing a significant relationship $(\mathrm{P}=0.0396)$. Despite the weak relationship, errors estimation in TLS-derived LL presents a decreasing trend that corresponds to length increase. Large wood having a length of between $1 \mathrm{~m}$ and $5 \mathrm{~m}$ features an errors estimation with a wide range of variability $(-84 \%,+30 \%)$, whereas LW more than $5 \mathrm{~m}$ in length presents a lower errors estimation within a narrower range (-5\%-50\%). Instead, TLSderived LD displays a not significant relationship with errors estimation. However, a value of $0.20 \mathrm{~m}$ can be identified as a threshold between errors with higher and lower variability. Lastly, the errors estimation in TLS-derived TCW shows no significant or clear relationships with shrub width.

Considering the volumetric results, the wood volume was computed from both the traditional survey and TLS results. Figure 9 presents the distribution of the relative differences between the manual and TLS method for wood volume calculation. It shows a tendency to overestimate the volume of wood jams using the TLS results. The majority of relative errors are in a range between $+2 \%$ and $+54 \%$, with a median value of about $+22 \%$. Different results were found concerning the LW, where the TLS shows an underestimation. Errors have a wider distribution ranging from positive to negative values, $+22 \%$ to $-75 \%$ respectively, with a median value of $-12 \%$.

For the length and volume data of each wood element there are acceptable relative errors between field validation data and those obtained using TLS. Table 1 reports the wood volumes for the entire study area, both for wood jams and large wood, extracted from traditional and TLS derived surveys. Considering the volume per hectare, it can be observed that the TLS method provides data very similar to those derived from the traditional measurements, with a slight underestima-
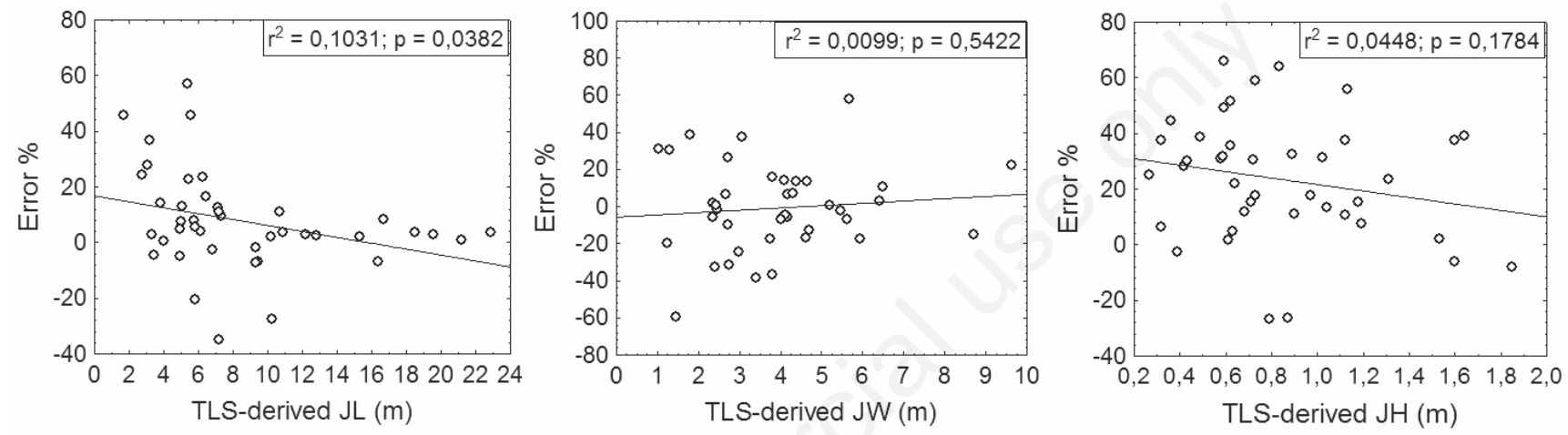

Figure 5. Errors estimation for terrestrial laser scanner (TLS)-derived wood jams measurements. JL, length; JW, width; JH, height.

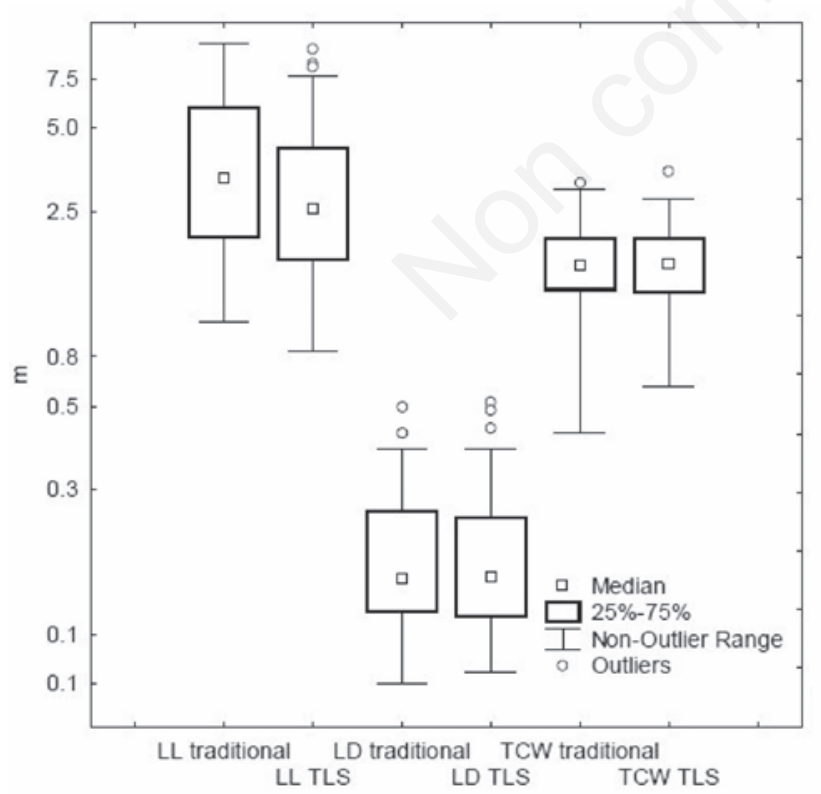

Figure 6. Comparison between traditional results and terrestrial laser scanner (TLS) results for the three main single wood measurements. Because of a wide range of measures, axes are given in a logarithmic scale for readability. LL, log length; LD, breast height; TCW, tree canopy width.

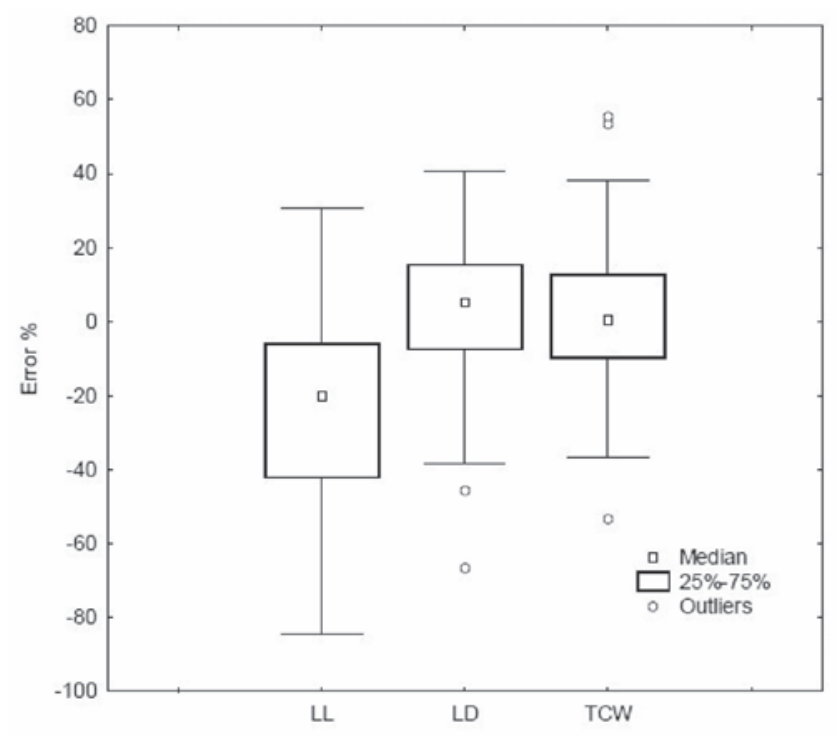

Figure 7. Relative differences of the terrestrial laser scanner method when compared to the manual ones for the three main single wood measurements estimation. LL, log length; LD, breast height; TCW, tree canopy width. 

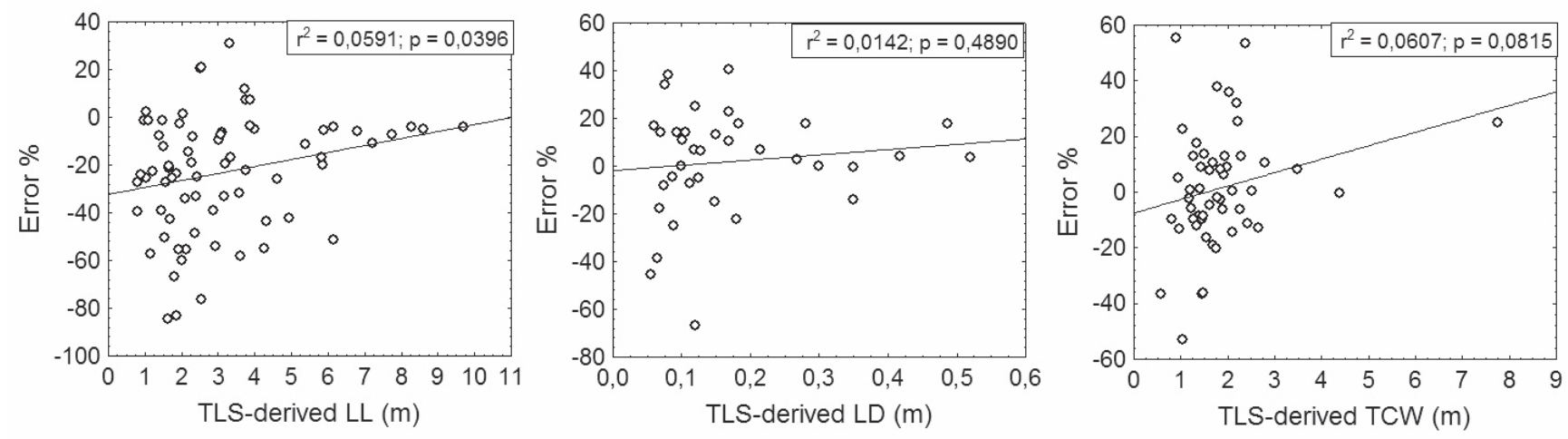

Figure 8. Errors estimation for terrestrial laser scanner (TLS)-derived single wood measurements. LL, log length; LD, breast height; TCW, tree canopy width.

tion of about $-26.65 \mathrm{~m}^{3} /$ ha for wood jams and an overestimation of $+14.39 \mathrm{~m}^{3} /$ ha for large wood. The estimation errors show strong decrease, in both cases the relative error can be approximated to $\pm 7 \%$.

During the TLS data analysis we also tested how it performs in terms of qualitative information of large wood. There is no doubt about the potential of the device to discriminate the type of wood, all the elements were easily distinguished as wood jams, single wood and, more specifically, logs, trees and shrubs. No difficulties were found in the detection of large wood orientation with respect to the flow direction. In addition, we analysed the possibility to obtain information about the distinction between conifers and deciduous, the taxonomic family and state of decay. The analysis shows quite good results only for the large wood and the distinction between conifers and deciduous; instead, the wood jams structure is too complex to permit any clear identification (Table 2).

\section{Discussion}

The results obtained using the TLS reveal the potential of this device in the detection of the main large wood characteristics. However, it is worth noting that, regarding the 3D point cloud analysis, it has not been possible to identify all the woody elements detected in the field. In fact, there is divergence of 22 elements (11 wood jams and 11 large woods) between the number measured in the field and those identified from the TLS data. Those unable to be extracted from the point cloud were located along the riverbanks or on the edges between the wetted area and the low bars, so this divergence is probably related to the geomorphic approach applied to the collection of data using the TLS. Indeed it is possible that some wood was not detected because of shadows, water or geomorphic discontinuity that does not permit a homogeneous point density.

Regarding the ability of TLS to correctly extract the wood measurements, the device provided very good results except for the JH and LL where greater estimation errors were found. The overestimation of JH should be due to the difficulty in $3 \mathrm{D}$ cloud management. In the traditional way, the height of WJ was measured taking care not to overestimate the air-wood volume, so thin branches and sprouts in the upper part of the WJ were not measured. With the point clouds, this type of height estimation was not easy to apply due to a low point density in the upper part of the wood jams because of the brushwood that does not permit us to clearly identify the sprouts, which is easier to do directly in the field. This could imply an overestimation of the WJ height. The

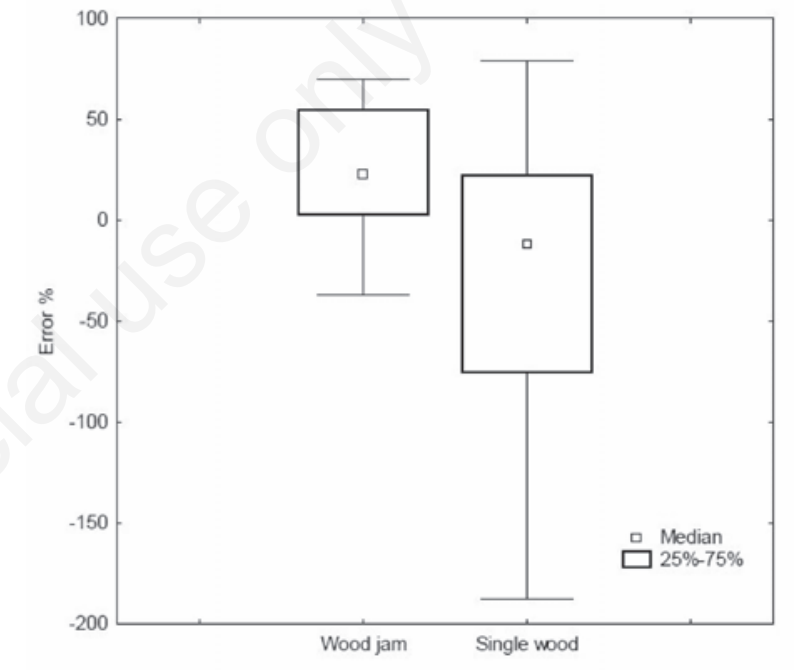

Figure 9. Relative differences of the terrestrial laser scanner method when compared to the manual ones for the large wood volume estimation.

Table 1. Comparison of large wood volume between the manual and terrestrial laser scanner methods.

\begin{tabular}{lcccc} 
& $\begin{array}{c}\text { Manual } \\
\mathrm{m}^{3} / \mathrm{ha}\end{array}$ & $\begin{array}{c}\text { TLS } \\
\mathrm{m}^{3} / \mathrm{ha}\end{array}$ & $\begin{array}{c}\text { Difference } \\
\mathrm{m}^{3} / \mathrm{ha}\end{array}$ & $\begin{array}{c}\text { Error } \\
\%\end{array}$ \\
Wood jams volume & 371.15 & 344.5 & -26.65 & -7.73 \\
Single wood volume & 189.71 & 204.1 & +14.39 & +7.05 \\
\hline
\end{tabular}

TLS, terrestrial laser scanner.

Table 2. Main large wood qualitative characteristics investigated on field data and terrestrial laser scanner data.

\begin{tabular}{lccccc} 
& LW & Orientation Conifer/ Taxonomic & State of \\
typology & & & Teciduous & family & decay \\
Traditional survey & Yes & Yes & Yes & Yes & Yes \\
TLS survey & Yes & Yes & Yes & No & No \\
\hline
\end{tabular}

LW, large wood; TLS, terrestrial laser scanner. 
divergence in the LL could be attributable to the way in which the length was measured. Traditionally, the length of a large wood was detected as the distance between the base and apex of the trunk, the roots were excluded to avoid a further overestimation of air-wood volume. Analysing the point clouds, it was not easy to identify a clear boundary between the roots and the trunk, and in some cases it was almost impossible to recognise the presence or absence of roots, notably for shrubs. So, some errors in the data analysis probably occurred.

Considering the volumetric results, the TLS has shown an irregular tendency to over or underestimate the wood volume and this is likely due to the previously mentioned errors: the overestimation of WJ volume reflects the overestimation in the WJ height and the underestimation of large wood volume is a consequence of the underestimation of LW length.

Results from the plotting between TLS-derived measurements and errors estimation have shown significant relationships only with length, for both wood jams and large wood, with decreasing errors corresponding to increasing lengths. This suggests that wood characteristics may also affect the ability of TLS to detect wood elements; indeed the presence of wood with large dimensions could provide better results in TLS surveys.

Despite the lack of similar studies that does not permit us to compare and discuss our results in more detail, they are supported by those found by Boivin and Buffin-Bélanger (2010) and Picco et al. (2011) although with a different survey scheme and method of data extraction.

Looking at the qualitative analysis, TLS appears to be as a reliable tool for providing additional data on wood characteristics, such as orientation with respect to the flow direction, shape and, as also shown by Boivin and Buffin-Bélanger (2010), wood porosity. More in detail and only for large wood, the device has proved capable of discriminating between conifers and deciduous thanks to the presence of foliage in the majority of woody elements. The fine needles of conifers are usually grouped together, whereas deciduous have wider and scattered leaves. The different kind of foliage involves a different distribution of laser points in the point cloud that permitted us to distinguish the two types. For the logs without leaves or branches, no reliable data have been provided on the distinction between conifers and deciduous. The TLS has not been able to provide accurate information on woody species and state of decay. These are, probably, too highly-detailed characteristics to be obtained using a geomorphic approach in the TLS surveys. In fact, as shown by Othmani et al. (2013), on the basis of ad hoc scans on small areas, it is possible to recognise the tree species from TLS data by analysing the 3D geometric texture of the bark.

Regarding the wood jams only quantitative data can be accurately extracted from the TLS point clouds, otherwise multiple scans from different positions around the WJ would be needed, in accordance with the methodology presented by Boivin and Buffin-Bélanger (2010).

From a methodological point of view, the TLS technology is a valid method to perform analysis with low time consumption, but the spatial distribution and device specifications must be carefully chosen according to the study objectives. For instance, in the case of studies aimed at the estimation of the wood budget at a sub-reach scale where information is needed on lateral recruitment of wood, TLS scans should also cover the riverbanks. In other cases, where the objective is the computation of in-channel wood volume, detailed scans from different positions around larger WJ are recommended to reduce the measurement estimation error. Moreover, as already stated by Picco et al. (2013), the main issue of TLS in a fluvial environment is the low point density on the wetted area that does not allow the recognition of possible partially-submerged woody elements. To overcome this it is recommended to perform scans during low water flow conditions.

\section{Conclusions}

The results demonstrate that the TLS can be a useful device to assess the main characteristics of wood present along a fluvial system, such as a gravel-bed river. The comparison between the conventional and TLS methods provided satisfactory results in the detection of the main wood characteristics needed for volume assessment. Higher error levels were found in WJ height and LW length estimation, causing a slight under and overestimation of wood volume. For future development, attention should focus on improving the analysis of 3D point clouds in order to enhance the extraction of wood characteristics. Nevertheless, negligible estimation errors found for the wood volume in the entire study area reveal the capacity of TLS to provide extensive information on the amount of wood at a medium spatial scale. The geomorphic approach adopted in the TLS surveys could be a new convenient method to scan wide areas with very accurate results.

From a river management point of view, the TLS should be considered as a suitable way to map the temporal and spatial variations of wood volumes. In fact, thanks to lower time and labour requirements than the traditional field activities, the TLS could be used to repeat surveys after single flood events to provide maps of morphological changes. All this information can be advantageous in the monitoring of fluvial hazards related to the presence of wood as well as for drawing up suitable river management programs.

\section{References}

Bater C.W., Coops N.C., Gergel S.E., Goodwin N.R. 2007. Towards the estimation of tree structural class in northwest coastal forests using lidar remote sensing. In Proc. ISPRS Workshop on Laser Scanning 2007 and SilviLaser 2007, 12-14 September, Espoo, Finland.

Bilby R.E., Ward J.W. 1989. Changes in characteristics and function of woody debris with increasing size of streams in western Washington. Trans. Am. Fish. Soc. 118:368-78.

Boivin M., Buffin-Bélanger T. 2010. Using a terrestrial LIDAR for monitoring of large woody debris jams in gravel-bed rivers. 7th Gravel bed Rivers Conference, 5-10 September 2010, Tadoussac, Quebec, Canada (poster).

Citterio A. 1996. Dynamique de prise en charge et de dépôt des débris ligneux dans les systèmes Ain et Drôme. Mémoire de maîtrise en géographie. Université Jean Moulin-Lyon 3, France, pp 72.

Comiti F., Da Canal M., Surian N., Mao L., Picco L., Lenzi M.A. 2011. Channel adjustments and vegetation cover dynamics in a large gravel bed river over the last 200 years. Geomorphology 125:147-59.

Comiti F., D’Agostino V., Moser M., Lenzi M.A., Bettella F., Agnese A., Rigon E., Gius S., Mazzorana B. 2012. Preventing wood-related hazards in mountain basins: from wood load estimation to designing retention structures. In: Research Society Interpraevent (ed.), 12th Congress INTERPRAEVENT, Conf. Proceedings, 23-26 April, Grenoble, France, 2:651-662.

Comiti F., Mao L., Preciso E., Picco L., Marchi L., Borga M. 2008. Large wood and flash floods: evidences from the 2007 event in the Dav a basin (Slovenia). Monitoring, simulation, prevention and remediation of dense and debris flow II. WIT Trans. Eng. Sci. 60:173-82.

Delai F., Moretto J., Picco L., Rigon E., Ravazzolo D., Lenzi M. A. 2014. Analysis of morphological processes in a disturbed gravel-bed river (Piave River): integration of LiDAR data and colour bathymetry. J. Civil Engine. Architect. 8:639-48.

Diehl T.H. 1997. Potential drift accumulation at bridges. US 
Department of Transportation, Federal Highway Administration Research and Development, Turner-Fairbank Highway Research Center, Virginia, Publication No. FHWA-RD-97-028.

Gurnell A., Tockner K., Edwards P., Petts G. 2005. Effects of deposited wood on biocomplexity of river corridors. Front. Ecol. Environ. $3: 377-82$.

Guyette R.P., Cole W.G., Dey D.C., Muzika R. 2002. Perspectives on the age and distribution of large wood in riparian carbon pools. Can. J. Fish. Aquat. Sci. 59:578-85.

Holopainen M., Talvitie M. 2007. Effect of data acquisition accuracy on timing of stand harvests and expected net present value. Silva Fennica 40:531-43.

Jackson C.R., Sturm C.A. 2002. Woody debris and channel morphology in first and second order forested channels in Washington's coast ranges. Water Resour. Res. 38:1177-90.

Kaless G., Mao L., Lenzi M.A. 2014. Regime theories in gravel-bed rivers: models, controlling variables, and applications in disturbed Italian rivers. Hydrol. Process. 28:2348-60.

Keller E.A., Swanson F.J. 1979. Effects of large organic material on channel form and fluvial processes. Earth Surface Proc. Land. 4:361-80.

Leopold L.B., Wolman M.G. 1957. River channel patterns: braided, meandering, and straight. U. S. Geol. Surv. Prof. Paper. 282B:39-85.

Mao L., Comiti F., Andreoli A., Picco L., Lenzi M. A., Urciuolo A., Iturraspe R., Iroumé A. 2008. Role and management of in-channel wood in relation to flood events in Southern Andes basins. Monitoring, simulation, prevention and remediation of dense and debris flow II. WIT Trans. Eng. Sci. 60:207-16.

Mazzorana B., Zischg A., Largiader A., Hübl J. 2009. Hazard index maps for woody material recruitment and transport in alpine catchments. Nat. Hazards Earth Syst. Sci. 9:197-209.

Montgomery D.R., Piégay H. 2003. Wood in rivers: interactions with channel morphology and processes. Geomorphology 51:1-5.

Næsset E. 2004. Practical large-scale forest stand inventory using a small-footprint airborne scanning laser. Scand. J. Forest Res. 19:164-79.

Othmani A., Lew F.C., Voon L.Y., Stolz C., Piboule A. 2013. Single tree species classification from terrestrial laser scanning data for forest inventory. Pattern Recogn. Lett. 34:2144-50.

Pfeifer N., Gorte B., Winterhalder D. 2004. Automatic reconstruction of single trees from terrestrial laser scanner data. pp 114-119 in Proc. 20th ISPRS Congress, 12-23 July, Istanbul, Turkey.

Picco L., Mao L., Cavalli M., Buzzi E., Rainato R., Lenzi M.A. 2013.
Evaluating short-term morphological changes in a gravel-bed braided river using terrestrial laser scanner. Geomorphology 201:323-34.

Picco L., Mao L., Rainato R., Lenzi M.A. 2014a. Medium term fluvial island evolution in a disturbed gravel bed river (Piave River, Northeastern Italian Alps). Geograf. Annal. Ser. A Phys. Geogr. 96:83-97.

Picco L., Mao L., Rigon E., Moretto J., Ravazzolo D., Delai F., Lenzi M.A. 2012a. An update of the sediment fluxes investigation in the Rio Cordon (Italy) after 25 years of monitoring. J. Agric. Engin. 43:108-13.

Picco L., Mao L., Rigon E., Moretto J., Ravazzolo D., Delai F., Lenzi M.A. 2012b. Riparian forest structure, vegetation cover and flood events in the Piave River. WIT Trans. Eng. Sci. 73:137-47.

Picco L., Ravazzolo D., Rainato R., Lenzi M.A. 2014b. Characteristics of fluvial islands along three gravel bed-rivers of North-Eastern Italy. Cuad. Invest.Geográf. 40:53-66.

Picco L., Vitti P., Mao L., Ravazzolo D., Rigon E., Moretto J., Lenzi M.A. 2011. Large woody debris measurements, in a gravel-bed braided river environment, using terrestrial laser scanner: the Piave River study case. In: EGU General Assembly, 3-8 April, Wien, Austria. Geophys. Res. Abstr. 13:EGU 2011-1555 (poster).

Piégay H. 1993. Nature, mass and preferential sites of coarse woody debris deposits in the lower Ain Valley (Mollon Reach), France. Regul. Rivers Res. Mgmt. 8:359-72.

Piégay H. 2003. Dynamics of wood in large rivers. Am. Fish. Soc. Symp. 37:109-33.

Rigon E., Comiti F., Lenzi M.A. 2012. Large wood storage in streams of the Eastern Italian Alps and the relevance of hillslope processes. Water Resour. Res. 48:W01J18.

Rosenfeld J.S., Huato L. 2003. Relationship between large woody debris characteristics and pool formation in small coastal British Columbia streams. N. Am. J. Fish. Manage. 23:928-38.

Seielstad C.A., Queen L.P. 2003. Using airborne laser altimetry to determine fuel models for estimating fire behavior. J. Forestry 101:10-5.

Surian N. 1999. Channel changes due to river regulation: the case of the Piave River, Italy. Earth Surface Proc. Land. 24:1135-51.

Thevenet A., Citterio A., Piegay H. 1998. A new methodology for the assessment of large woody debris accumulations on highly modified rivers (example of two French Piedmont rivers). Regul. Rivers Res. Mgmt. 14:467-83.

Wohl E. 2013. Floodplains and wood. Earth Sci. Rev. 123:194-212. 